\title{
Response Selectivity Is Correlated to Dendritic Structure in Parvalbumin-Expressing Inhibitory Neurons in Visual Cortex
}

\author{
Caroline A. Runyan and Mriganka Sur \\ Department of Brain and Cognitive Sciences, Picower Institute for Learning and Memory, Massachusetts Institute of Technology, Cambridge, \\ Massachusetts 02139
}

Inhibitory neurons have been shown to perform a variety of functions within brain circuits, including shaping response functions in target cells. Still, how the properties of specific inhibitory neuron classes relate to their local circuits remains unclear. To better understand the distribution and origins of orientation selectivity in inhibitory neurons expressing the calcium binding protein parvalbumin $(\mathrm{PV})$ in the mouse primary visual cortex, we labeled $\mathrm{PV}^{+}$neurons with red fluorescent protein (RFP) and targeted them for cell-attached electrophysiological recordings. $\mathrm{PV}^{+}$neurons could be broadly tuned or sharply tuned for orientation but tended to be more broadly tuned than unlabeled neurons on average. The dendritic morphology of $\mathrm{PV}^{+}$cells, revealed by intracellular labeling, was strongly correlated with tuning: highly tuned $\mathrm{PV}^{+}$neurons had shorter dendrites that branched nearer to the soma and had smaller dendritic fields overall, whereas broadly tuned $\mathrm{PV}^{+}$neurons had longer dendrites that branched farther from the soma, producing larger dendritic fields. High-speed two-photon calcium imaging of visual responses showed that the orientation preferences of highly tuned PV ${ }^{+}$neurons resembled the preferred orientations of neighboring cells. These results suggest that the diversity of the local neighborhood and the nature of dendritic sampling may both contribute to the response selectivity of $\mathrm{PV}^{+}$neurons.

\section{Introduction}

Inhibition has diverse roles in cortical circuits (Pouille and Scanziani, 2001; Wehr and Zador, 2003; Mariño et al., 2005; Cardin et al., 2009; Adesnik et al., 2012; Atallah et al., 2012; Lee et al., 2012; LovettBarron et al., 2012; Royer et al., 2012; Wilson et al., 2012). This diversity of function matches the diversity of the inhibitory population. Inhibitory neuron subclasses differ in their gene expression, axonal projection patterns, dendritic morphology, and electrophysiological properties, suggesting that specific subtypes may perform specific functions (Markram et al., 2004; Somogyi and Klausberger, 2005; Burkhalter, 2008; Isaacson and Scanziani, 2011).

Parvalbumin-positive $\left(\mathrm{PV}^{+}\right)$cells, often considered one distinct cell type, are heterogeneous across all of these dimensions. Morphologically, they include soma-targeting basket cells with small and large dendritic and axonal fields, axon-targeting chan-

Received May 7, 2012; revised May 31, 2013; accepted June 9, 2013.

Author contributions: C.A.R. and M.S. designed research; C.A.R. performed research; C.A.R. analyzed data; C.A.R. and M.S. wrote the paper.

This work was supported by National Research Service Award NS679512 (C.A.R.), National Institutes of Health Grants EY007023 and EY018041 (M.S.), and the Simons Foundation (M.S.). We thank Nathan Wilson for developing the two-photon targeted fast scan software, and the members of the M.S. laboratory for useful discussions and feedback.

The authors declare no competing financial interests.

Correspondence should be addressed to either of the following: Dr. Caroline A. Runyan, Department of Neurobiology, Harvard Medical School, 200 Longwood Avenue, Boston, MA 02115, E-mail: caroline_runyan@hms.harvard.edu; or Dr. Mriganka Sur, Department of Brain and Cognitive Sciences, Massachusetts Institute of Technology, 77 Massachusetts Avenue, Cambridge, MA 02139, E-mail: msur@mit.edu.

C.A. Runyan's present address: Department of Neurobiology, Harvard Medical School, Boston, MA 02115.

DOI:10.1523/JNEUROSCI.2196-12.2013

Copyright $\odot 2013$ the authors $\quad 0270-6474 / 13 / 3311724-10 \$ 15.00 / 0$ delier cells, and dendrite-targeting multipolar bursting cells (Kisvárday and Eysel, 1993; Lund and Lewis, 1993; Han, 1994; Wang et al., 2002; Blatow et al., 2003; Krimer et al., 2005; Zaitsev et al., 2009). $\mathrm{PV}^{+}$neurons also vary in expression of potassium channel subunits (Du et al., 1996; Chow et al., 1999), calcium binding proteins (Chow et al., 1999; Blatow et al., 2003), and other signaling molecules and receptors (Yan et al., 1998; Vruwink et al., 2001). Most $\mathrm{PV}^{+}$neurons are fast-spiking, responding to current injections with barrages of narrow spikes; however, some $\mathrm{PV}^{+}$ neurons are regular-spiking or stuttering (Han, 1994; Blatow et al., 2003; Markram et al., 2004; Krimer et al., 2005), and $\mathrm{PV}^{+}$ basket cells include at least four electrophysiological subtypes (Helm et al., 2013).

The $\mathrm{PV}^{+}$population is also functionally diverse; in visual cortex (V1), these cells have receptive fields that range from unselective to highly selective for orientation and other response features (Sohya et al., 2007; Liu et al., 2009; Kerlin et al., 2010; Runyan et al., 2010; Hofer et al., 2011). The origins of $\mathrm{PV}^{+}$neuron tuning remain unresolved but might depend on the specificity of local inputs to these cells. The salt-and-pepper organization of orientation preferences in mouse V1 (Ohki and Reid, 2007), coupled with uniformly sampled inputs from the orientation map, could provide broad orientation tuning to $\mathrm{PV}^{+}$cells, whereas narrow tuning would require precisely selected inputs. On the other hand, small homogeneities in the orientation representation (Dräger, 1975), coupled with matched dendritic arbors of a subset of $\mathrm{PV}^{+}$neurons, could enable these neurons to achieve narrow tuning by uniform sampling of the local neighborhood alone. 
We recorded from a large number of $\mathrm{PV}^{+}$neurons and found that highly tuned $\mathrm{PV}^{+}$neurons have smaller dendritic fields and shorter dendrites, whereas broadly tuned $\mathrm{PV}^{+}$neurons have larger dendritic fields and longer, more tortuous dendrites. We then compared the spatial distribution of orientation preferences of the neurons surrounding $\mathrm{PV}^{+}$neurons, finding that the orientation preferences of $\mathrm{PV}^{+}$neurons resembled those of nearby cells, suggesting that these neurons may sample uniformly from local inputs, and the breadth of their dendritic arbors may influence their response selectivity by restricting the number and diversity of their inputs.

\section{Materials and Methods}

Mice. Experiments were performed in mice of either sex under protocols approved by Massachusetts Institute of Technology's Animal Care and Use Committee and conformed to National Institutes of Health guidelines. Heterozygous $P V$-Cre knock-in driver mice, which express Cre in $>90 \%$ of $\mathrm{PV}^{+}$neurons, were backcrossed into a C57BL/6 line (Hippenmeyer et al., 2005) and used for the analysis of $\mathrm{PV}^{+}$and $\mathrm{PV}^{-}$neurons. Thy1-GFP-S mice (Feng et al., 2000), in which a subset of superficial layer neurons are labeled, were also maintained on a C57BL/6 line and were used for the analysis of pyramidal neurons.

Viral construct and injection. Red fluorescent protein (RFP) was expressed in $\mathrm{PV}^{+}$neurons in $\mathrm{V} 1$ of $\mathrm{PV}$-Cre mice by infection of an $\mathrm{LS}_{2} \mathrm{~L}$ RFP construct packaged into adeno-associated virus (serotype 2/9) as described previously (Kuhlman and Huang, 2008; Runyan et al., 2010). Six-week-old $P V$-Cre mice were initially anesthetized with $4 \%$ isoflurane in oxygen and maintained on $2 \%$ isoflurane. The skull was thinned along a $1 \mathrm{~mm}$ line at the rostral edge of V1, and the remaining skull and dura mater were carefully punctured using a glass micropipette filled with the virus. Two injections $(0.25 \mu \mathrm{l}$ of virus, injected at $10 \mathrm{nl} / \mathrm{min})$ were made at each site, at depths of 500 and $250 \mu \mathrm{m}$, respectively. After each injection, the pipette was held in place for $5 \mathrm{~min}$ before retraction to prevent leakage.

Animal preparation. Two to four weeks after injection, mice were anesthetized with a mixture containing fentanyl $(0.05 \mathrm{mg} / \mathrm{kg})$, midazolam $(5$ $\mathrm{mg} / \mathrm{kg})$, and medetomidine $(0.5 \mathrm{mg} / \mathrm{kg})$, supplemented with isoflurane. The eyes were protected with ophthalmic ointment during the surgery and moistened afterward with saline. A metal head plate was attached to the skull parallel to V1 using cyanoacrylate glue and dental acrylic. A 2 $\mathrm{mm} \times 2 \mathrm{~mm}$ craniotomy was performed over $\mathrm{V} 1$, and the exposed area was covered with a thin layer of $2 \%$ agarose in ACSF ( $140 \mathrm{~mm} \mathrm{NaCl}, 5 \mathrm{~mm}$ $\mathrm{KCl}, 2 \mathrm{~mm} \mathrm{CaCl}$, $1 \mathrm{~mm} \mathrm{MgCl}_{2}, 0.01 \mathrm{~mm}$ EDTA, $10 \mathrm{~mm}$ HEPES, $10 \mathrm{~mm}$ glucose, $\mathrm{pH}$ 7.4).

Mice were then transferred to a custom-built two-photon microscope (Majewska et al., 2000) that was powered by a Spectra Physics Mai-Tai eHP laser, passed through a Deep-See module (Spectra Physics), where the head plate was screwed into a moveable stage. To maintain anesthesia, $0.5 \%$ isoflurane in oxygen was supplied through a tube, and fentanyl/ medetomidine was injected every hour. The body temperature was maintained at $37.5^{\circ} \mathrm{C}$ with heating pads. The recording phase of physiology experiments typically lasted for 6-12 h.

Targeted cell-attached recording. Glass pipettes with $\sim 1.5 \mu \mathrm{m}$ tip size and 3-7 M $\Omega$ resistance were filled with AlexaFluor-488 (5 $\mu \mathrm{M}$ in saline, Invitrogen) and angled into the pia above the viral injection site using a micromanipulator (Sutter, MP-285) under visual guidance with epifluorescence. Upon entering the brain, the pipette was guided toward RFP ${ }^{+}$ cells in superficial layer 2/3 of V1 under two-photon guidance. The laser was tuned to $920 \mathrm{~nm}$, which allowed excitation of both the Alexa-488 and RFP fluorophores simultaneously. The pipette was targeted to $\mathrm{RFP}^{+}$cells while applying constant positive pressure $(0.2 \mathrm{psi})$, which was monitored with a digital pressure gauge (General Tools). When the pipette just touched the cell surface, positive pressure was released, and sustained negative pressure immediately applied $(0.2-0.6 \mathrm{psi})$ to obtain a loose seal (Runyan et al., 2010). Cells from which well-isolated spikes were detected during the display of a drifting grating that randomly changed orientation and direction at $8 \mathrm{~Hz}$ were characterized further, and their orientation selectivity was assessed. Subsequently, current pulses (35 ms, $900-$
$2000 \mathrm{nA}$ ) were delivered at $15 \mathrm{~Hz}$ for $30-60 \mathrm{~s}$ to fill the recorded cell through electroporation. Only single $\mathrm{RFP}^{+}$cells that were distinctly filled during this procedure were included for analysis. In the same experiments, $\mathrm{RFP}^{-}$cells were targeted blindly. As the tip was slowly advanced through the cortex, $-0.5 \mathrm{nA}$ current pulses were delivered for 6.3 $\mathrm{ms}$ at $0.55 \mathrm{~Hz}$, and the tip resistance was monitored. When the tip resistance increased substantially, positive pressure was released, and negative pressure immediately applied, as above. The location of the tip was still monitored under two-photon guidance; all $\mathrm{RFP}^{-}$cells were located within the injection site and were also filled after recording. Recordings from $\mathrm{GFP}^{+}$pyramidal neurons in Thy1-GFP-S mice were performed similarly. Neurons in PV-Cre or Thyl mice were targeted at depths of 100-300 $\mu \mathrm{m}$. Recordings were made with an Axoclamp-2A amplifier (Molecular Devices) using Clampex software (Molecular Devices, v8.1) at a sampling rate of $30 \mathrm{kHz}$.

Two-photon structural imaging. The laser was tuned to $920 \mathrm{~nm}$, allowing strong excitation of GFP, RFP, and Alexa-488. Images were collected through a high performance objective lens $(25 \times$ Olympus XL Plan N objective, NA $=1.05)$. $z$-stacks were collected tangentially, at $2 \mu \mathrm{m}$ increments from the pial surface through the extent of the filled cell, at resolution of $0.4 \mu \mathrm{m} /$ pixel, spanning $200-400 \mu \mathrm{m}$ in $x$ and $y$ dimensions, using FluoView300 confocal imaging software (Olympus), on both the red $\left(\mathrm{RFP}^{+}\right)$and green (Alexa-488 dye) channels. In all filled cells, the signal on red and green channels overlapped throughout all processes, and photomultiplier tube gain was optimized to visualize the finest processes.

Two-photon calcium imaging. For these experiments, we used a Prairie Ultima two-photon system (Prairie Technologies) driven by a Spectra Physics Mai-Tai eHP laser, passed through a Deep-See module (Spectra Physics). The excitation laser was tuned to $920 \mathrm{~nm}$, and functional imaging was done through a high performance objective lens $(25 \times$ Olympus XL Plan N objective, NA = 1.05).

A glass pipette filled with Oregon Green Bapta-1 AM (1.0 mM, Invitrogen) and AlexaFluor-594 (100 $\mu \mathrm{M}$, Invitrogen) was visually guided into the brain and lowered to a depth between 100 and $200 \mu \mathrm{m}$ below the surface, near the center of the viral injection site, and a small amount of dye was released using a picospritzer. The brain was then left undisturbed for at least $1 \mathrm{~h}$ before imaging.

We used a custom software system to measure changes in the calcium indicator fluorescence in response to visual stimuli, as described previously in detail (Wilson et al., 2012, 2013). Briefly, a raster scan was performed and machine vision algorithms were used to identify cell bodies. Next, an algorithm was used to identify the shortest scan path between cells, and this line scan was run at $50 \mathrm{~Hz}$, with a $90 \%$ dwell time inside the cells (only 10\% dwell time in neuropil), yielding high signal:noise fluorescent signals.

Visual stimulation. Visual stimuli were displayed on a 17-inch LCD monitor placed $15 \mathrm{~cm}$ from the eyes. Stimuli were generated in MATLAB (Mathworks) using the PsychoPhysics Toolbox (Brainard, 1997). Square wave drifting gratings with $100 \%$ contrast were used. In targeted cell-attached recordings, spatial frequency and temporal frequency were optimized to achieve the highest firing rate for each cell: spatial frequency ranged from 0.005 to 0.05 cycles per degree (cpd), and temporal frequency ranged from 1 to 3 cycles per second (cps). Test stimuli were episodically presented, equally alternating with a blank gray screen, with $8 \mathrm{~s}$ cycles ( $4 \mathrm{~s}$ on, $4 \mathrm{~s}$ off) at each of 18 directions equally spaced by 20 degrees.

Data analysis: visual responses. Analysis of all data was performed off-line with custom written MATLAB routines. Electrophysiological time traces were imported into MATLAB, smoothed with a Gaussian kernel, and spikes were identified by detection of events based on the derivative of the voltage traces. The spontaneous firing rate of each neuron was measured for $10 \mathrm{~s}$ preceding visual stimulation for each trial. A neuron was considered visually responsive if its firing rate at the preferred orientation was significantly higher than its spontaneous firing rate, determined with a $t$ test. The spontaneous firing rate was subtracted from the response to each orientation, the mean firing rate across the entire $4 \mathrm{~s}$ stimulus interval. The response firing rates were then fit to a Gaussian function.

Fluorescence time traces were assigned to the appropriate cell location, to obtain a time trace sampled at $50 \mathrm{~Hz}$. The response $(\Delta \mathrm{F} / \mathrm{F})$ was calcu- 
A

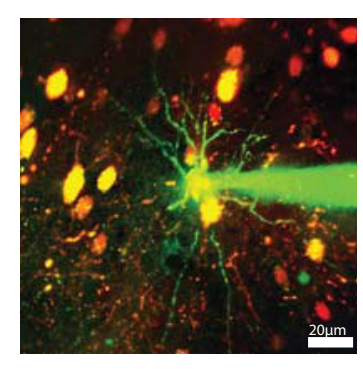

B

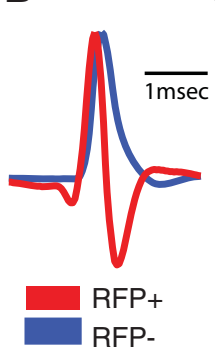

C

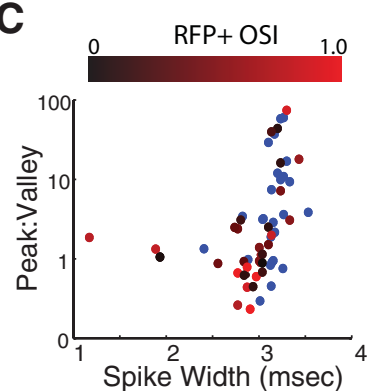

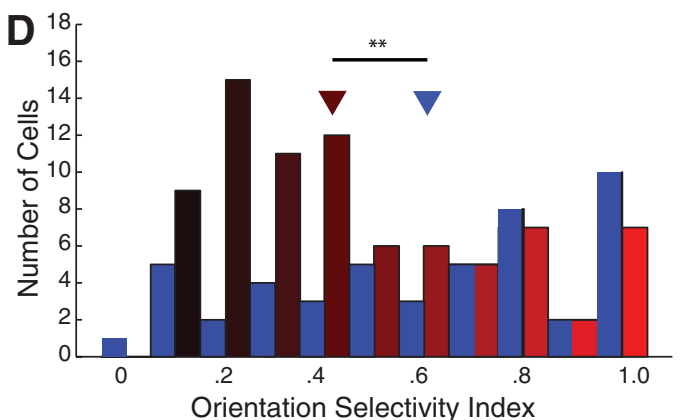

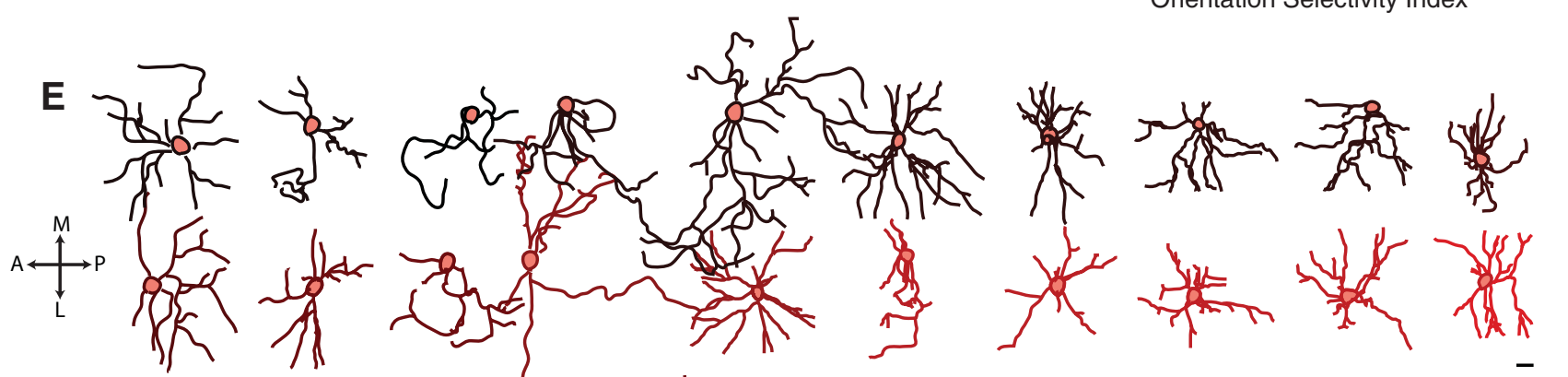

$\mathbf{F}$

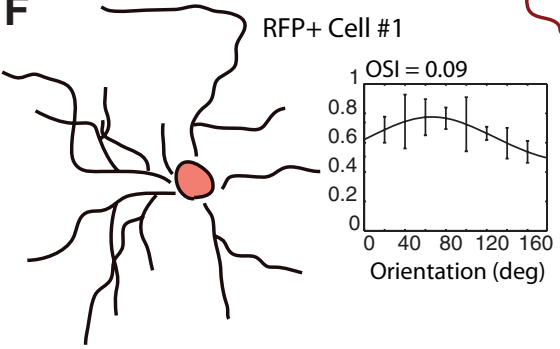

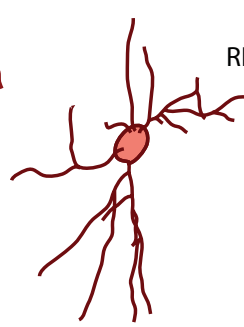

RFP+ Cell \#12
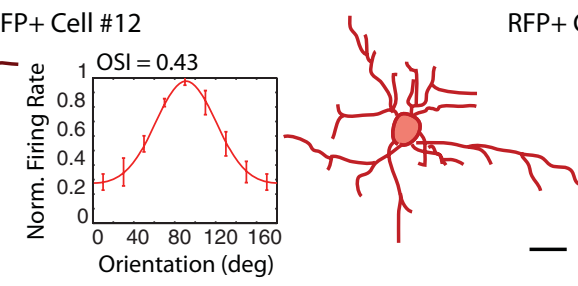

RFP+ Cell \#18

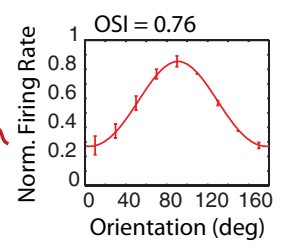

Figure 1. Relating structure and function in $\mathrm{PV}^{+}$neurons in vivo. $A$, The orientation selectivity of RFP ${ }^{+}$neurons and RFP ${ }^{-}$neurons was characterized in the primary visual cortex of $P V$ - $C r e$ mice injected with a floxed-RFP viral construct. RFP ${ }^{+}$neurons were targeted for recording under two-photon guidance, with a patch pipette containing green dye (Alexa-488). Each cell was then electroporated with the dye, and a z-stack was collected through the extent of the dendritic tree to enable morphological reconstruction. Scale bar, $20 \mu \mathrm{m} . \boldsymbol{B}$, Spikes recorded from RFP ${ }^{+}$neurons (red) and RFP ${ }^{-}$neurons (blue) were averaged and normalized by their maximum voltage. Spikes recorded from the RFP ${ }^{+}$neurons showed the characteristic shape of fast-spiking PV ${ }^{+}$neurons, including a strong afterhyperpolarization. C, The spike shapes of RFP ${ }^{+}$neurons and RFP ${ }^{-}$neurons were distinguishable by the ratio of peak to valley amplitude and spike width. RFP ${ }^{+}$neurons are color-coded by their OSI, demonstrating that spike shape in RFP ${ }^{+}$neurons did not predict orientation selectivity $(p>0.3)$. D, The histogram of OSIs of RFP ${ }^{+}$(red, shaded by OSI) and RFP ${ }^{-}$(blue) neurons reveals a wide range of orientation selectivity in both $\mathrm{RFP}^{+}$and $\mathrm{RFP}^{-}$neurons, although RFP ${ }^{+}$neurons tended to be more broadly tuned than $\mathrm{RFP}^{-}$neurons on average $(p<0.01) . \boldsymbol{E}$, Twenty RFP ${ }^{+}$neurons were reconstructed (see Materials and Methods), flattened through the z-plane (dorsal-ventral) for illustration purposes only, and color-coded by 0 SI as in $\mathbf{C}-\boldsymbol{D}$. All neurons are oriented similarly, as if in a tangential section. $A$, Anterior; $P$, posterior; $M$, medial; L, lateral. $F$, Three representative examples across the 0SI range are shown, along with their orientation tuning curves. Error bars on tuning curves indicate SEM. Cell numbers indicate the cell IDs from Table 1. Scale bars: $\boldsymbol{E}, \boldsymbol{F}, 20 \mu \mathrm{m} .{ }^{* *} p<0.01$.

lated for each time point by subtracting and then dividing the fluorescence value by the mean fluorescence of the surrounding 100 time points. The maximum $\Delta \mathrm{F} / \mathrm{F}$ during each grating presentation was taken as the visual response (Schummers et al., 2008; Runyan et al., 2010).

The orientation selectivity index (OSI) was calculated as the vector average of responses in the preferred direction (Schummers et al., 2002). Statistical comparisons were performed using the Wilcoxon test, twotailed $t$ test, and the Kolmogorov-Smirnoff test and yielded indistinguishable results. Values from two-tailed $t$ tests are reported in Results.

In the population calcium imaging datasets, the spatial arrangement of orientation preferences was assessed by calculating the local orientation scatter, or the mean difference in the preferred orientations of each cell and neighboring cells within $60,90,120$, or $240 \mu \mathrm{m}$. This mean difference was compared between RFP ${ }^{+}$cells and their neighbors and $\mathrm{RFP}^{-}$ cells and their neighbors. To test the validity of the difference between the orientation mapping around $\mathrm{RFP}^{+}$and $\mathrm{RFP}^{-}$neurons, a bootstrap procedure with 10,000 samples was used to estimate the orientation mapping in the randomized configuration, where the orientation preferences were resampled among the cells' spatial locations with replacement, and the local scatter around each cell was recalculated in each scrambled iteration (Dombeck et al., 2009).

Morphological reconstructions. Neurons were reconstructed from tangential $z$-stacks that were collected in vivo, as described above, using V3D semiautomatic tracing software (Peng et al., 2010). The multi-TIF 16-bit image stacks collected with the FluoView software were converted to high-contrast 8-bit images within ImageJ software and then imported into V3D. The contrast of each image was enhanced to allow the tracing of each thin dendritic process. Both the red $\left(\mathrm{RFP}^{+}\right)$and green (Alexa488) channels were used to follow all of the neuron's major and minor processes from the soma. Within the V3D software, stacks were carefully scrolled through to distinguish each process and to mark each insertion, branch, and tip location.

The 3D coordinates of the soma, dendritic insertion points, dendritic branches, and dendritic tips were then exported to MATLAB, where custom written software was used for the Sholl analysis (Gutierrez and Davies, 2007). The number of Sholl crossings was assessed at $20 \mu \mathrm{m}$ increments. For each neuron, the Sholl profile was fit to a Gaussian function, from which the peak number of crossings (amplitude) and distance of the peak from the soma (displacement) were extracted. The maximal dendritic extent was calculated as the distance from the soma to the most distal dendritic tip, and the dendritic field volume was calculated by computing the convex hull of the $3 \mathrm{D}$ dendritic tip coordinates. The polarity of the dendritic branching was assessed as follows. The direction of each branch and tip relative to the soma in each of the three cardinal planes was measured. In each plane, a Dendritic Polarity Index 
A Dendritic length, extent correlates with tuning
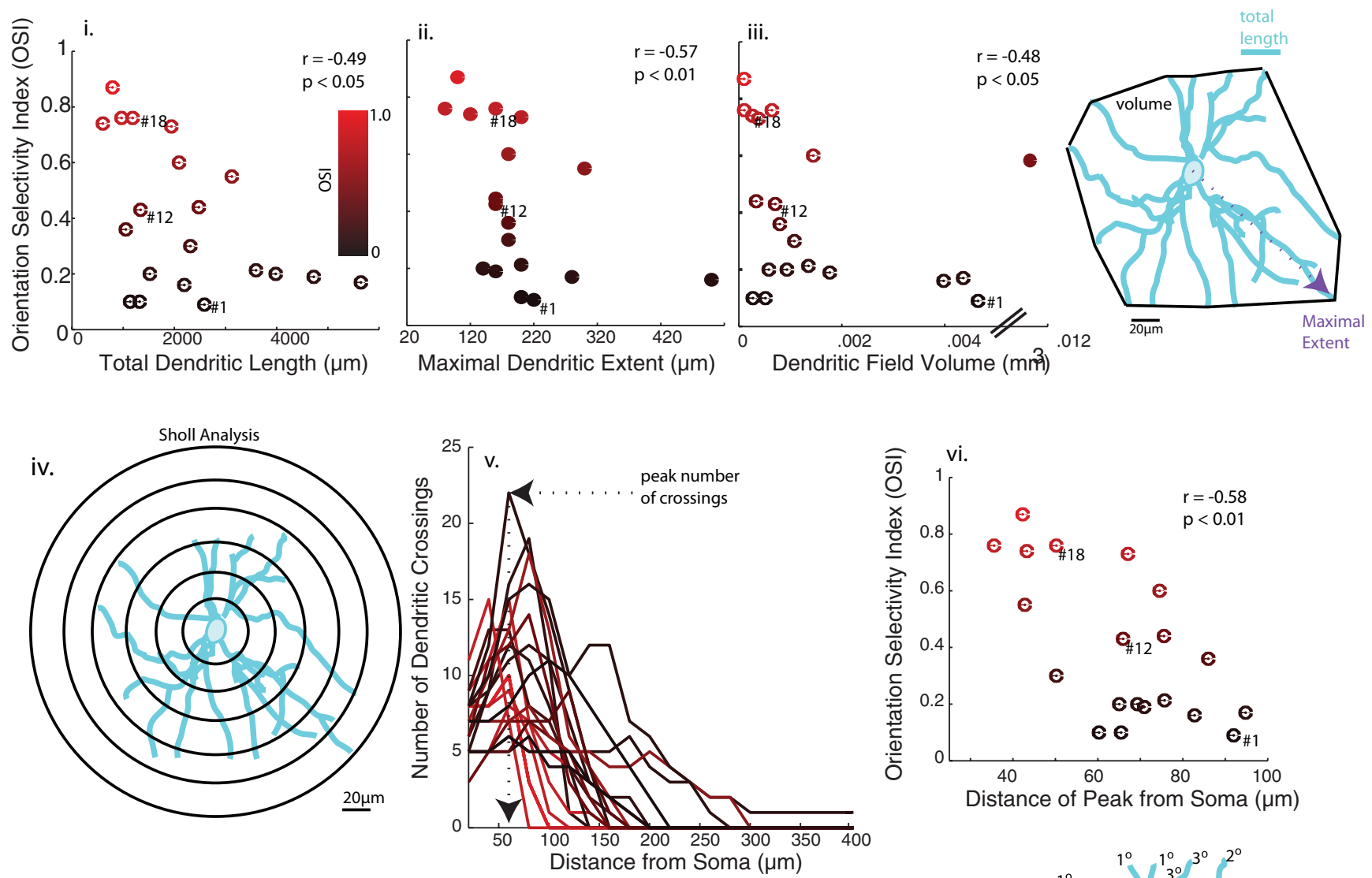

B Dendritic branching complexity does not correlate with tuning
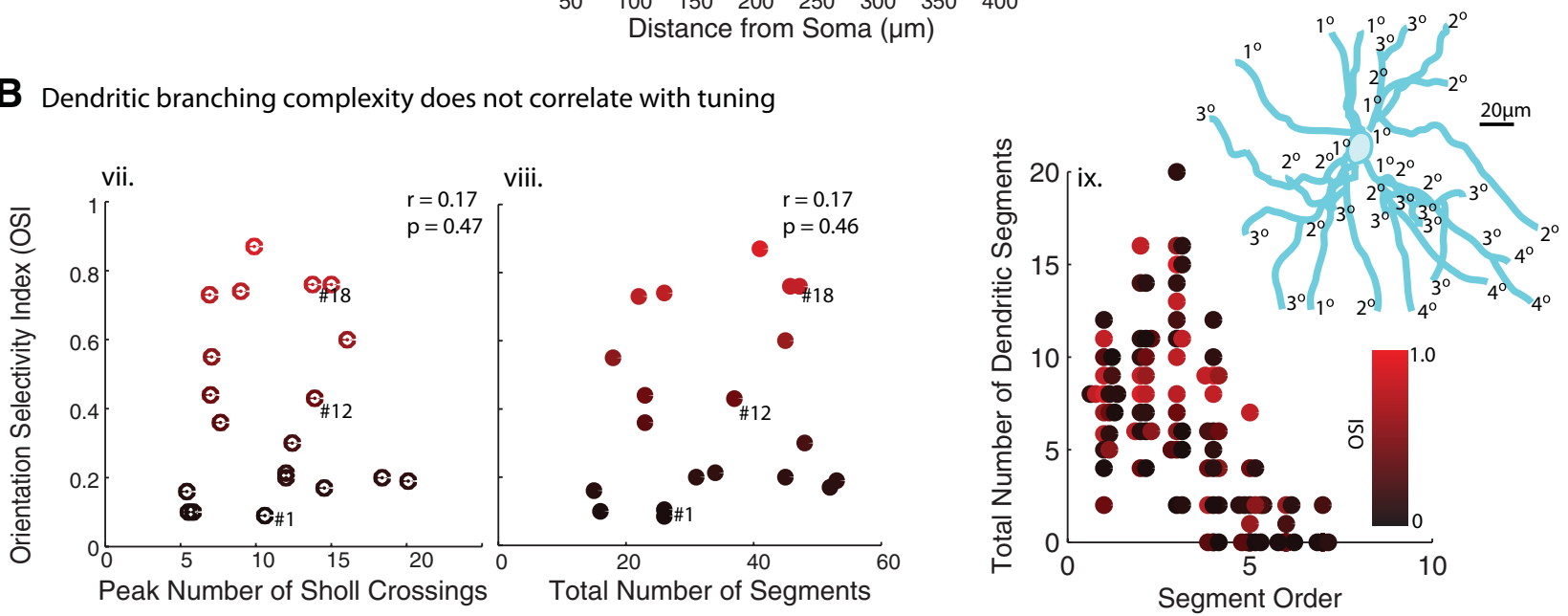

Figure 2. Dendritic extent, but not dendritic complexity, correlates with orientation selectivity of $\mathrm{PV}^{+}$neurons. $A$, All four measures of dendritic extent were significantly correlated with the $0 \mathrm{SI}$ of RFP ${ }^{+}$neurons: $\boldsymbol{i}$, The total dendritic length, the sum of the lengths of all dendrites; $i i$, the maximal dendritic extent, the distance of the most distal dendritic tip from the soma; iii, the dendritic field volume, the convex volume enclosed by the 3D coordinates of the neuron's tips; iv-vi, the distance of the Sholl peak from the soma were used to assess the spatial spread of dendritic integration by RFP ${ }^{+}$neurons. $\boldsymbol{B}$, Dendritic complexity, assessed by the peak number of Sholl crossings (vii; illustrated in iv, $\boldsymbol{v}$ ), the total number of dendritic segments (viii), and the number of higher-order dendritic segments (ix), did not significantly correlate with OSI. Data points corresponding to the example cells of Figure 2 are indicated by their ID numbers.

(DPI) was then calculated by vector averaging the distances of the tips and branches around the soma.

$\mathrm{RFP}^{+}$neurons from brains of $P V$-Cre mice were reconstructed in vitro for comparison with the in vivo reconstructions using the RFP label. The Alexa-488 dye in neurons imaged in vivo did not survive perfusion, and so the same cells were not imaged in vivo and in vitro. Coronal slices were collected at $100 \mu \mathrm{m}$ thickness, mounted on slides, and coverslipped. $z$-stacks were collected at $1 \mu \mathrm{m}$ optical slices at $4 \mu \mathrm{m}$ per pixel on a Zeiss LSM 5 Pascal Exciter confocal microscope with the 543 laser line RFP $^{+}$ fluorophore), and neurons were reconstructed as above.

\section{Results}

Electrophysiological properties of $\mathrm{PV}^{+}$neurons

We expressed RFP in $\mathrm{PV}^{+}$inhibitory interneurons in heterozygous PV-Cre knock-in mice (Kuhlman and Huang, 2008; Runyan et al., 2010) and used two-photon targeted cell-attached recording (Fig. 1A) to characterize 80 visually responsive $\mathrm{RFP}^{+}$neurons and 49 visually responsive $\mathrm{RFP}^{-}$neurons in V1 of $32 \mathrm{PV}$-Cre mice. The spike shapes of the RFP ${ }^{+}$and $\mathrm{RFP}^{-}$neurons were distinguishable (Fig. $1 B, C$ ): the $\mathrm{RFP}^{+}$neurons had narrower 
spike widths (mean $\pm \mathrm{SD}: \mathrm{RFP}^{+}, 2.9 \pm$ $0.4 \mathrm{~ms} \mathrm{RFP}^{-}, 3.1 \pm 0.2 \mathrm{~ms} ; p<0.01$, two-tailed two-sample $t$ test here and below), and similar peak/valley amplitudes $\left(\mathrm{RFP}^{+}, 6.7 \pm 15.5 \mathrm{RFP}^{-}, 10.4 \pm 16.5\right.$; $p=0.37)$ and repolarization rates $\left(\mathrm{RFP}^{+}\right.$, $3.1 \pm 2.3 \mathrm{~V} / \mathrm{s} ; \mathrm{RFP}^{-}, 2.8 \pm 1.8 \mathrm{~V} / \mathrm{s}, p=$ $0.61)$. The spontaneous firing rate was higher in the RFP ${ }^{+}$neurons $\left(\mathrm{RFP}^{+}, 1.2 \pm\right.$ $\left.2.0 \mathrm{~Hz} ; \mathrm{RFP}^{-}, 0.4 \pm 0.7 \mathrm{~Hz} ; p<0.01\right)$, but the two populations had similar visually evoked firing rates $\left(\mathrm{RFP}^{+}, 5.8 \pm 5.9 \mathrm{~Hz}\right.$; $\left.\mathrm{RFP}^{-}, 5.3 \pm 6.4 \mathrm{~Hz} ; p=0.67\right)$.

\section{Tuning properties of $\mathrm{PV}^{+}$neurons}

The diverse response features of $\mathrm{PV}^{+}$ neurons have been previously described by us (Runyan et al., 2010) and others (Liu et al., 2009; Kerlin et al., 2010; Hofer et al., 2011; Zariwala et al., 2011). We aimed in this study to carefully evaluate the orientation selectivity of a large population of these neurons and to compare their morphological features to their response selectivity. For each neuron, we measured the response to 18 drifting gratings in 20degree increments and calculated an OSI by vector averaging the response; the OSI can range from 0 (unselective for orientation) to 1 (responsive to only one orientation). On average, the OSIs were lower in the $\mathrm{RFP}^{+}$population $\left(\mathrm{RFP}^{+}, 0.46 \pm 0.28\right.$, $n=80 ; \mathrm{RFP}^{-}, 0.61 \pm 0.31, n=49 ; p<$ 0.01 ), although both populations included very broadly tuned and very sharply tuned cells (Fig. 1D). All recorded $\mathrm{RFP}^{+}$cells were located between 115 and $300 \mu \mathrm{m}$ below the pial surface (mean depth, $173 \pm 70 \mu \mathrm{m}$ ), and soma depth and orientation selectivity were not correlated $(r=0.18$, $p=0.13$ ). In addition, although not all $\mathrm{RFP}^{+}$neurons showed the narrow-spike profile typical of fast-spiking $\mathrm{PV}^{+}$neurons (Fig. 1C), none of the measured spike shape parameters correlated significantly with OSI (spike width, $r=0.15, p=0.37$; peak/valley, $r=0.07, p=0.77$; repolarization rate, $r=-0.15$, $p=0.54)$. Thus, it is unlikely that the highly selective $\mathrm{PV}^{+}$ neurons were a depth-based subclass, such as multipolar bursting cells, a subclass of regular-spiking $\mathrm{PV}^{+}$neurons that is located primarily at the border between layers I and II (Blatow et al., 2003) (i.e., at typical depths of 90-100 $\mu \mathrm{m}$ ).

\section{Morphology of $\mathrm{PV}^{+}$neurons: dendritic extent, but not complexity, correlates with orientation selectivity}

Differing tuning strength may indicate the existence of functional subclasses of $\mathrm{PV}^{+}$neurons that correspond to morphological subclasses, so we reconstructed the dendritic morphology of 20 $\mathrm{RFP}^{+}$neurons for which we had also measured orientation selectivity (Fig. 1E). After each cell's orientation tuning was characterized, it was filled with Alexa-488 (green) dye from the recording pipette, and a detailed $z$-stack in tangential view was collected through the extent of its dendritic tree on both the red and green channels with two-photon imaging.

The orientation selectivity of reconstructed $\mathrm{RFP}^{+}$neurons represented the full range of broadly tuned and highly tuned OSIs we described in Figure $1 D(0.09-0.87)$. Qualitative examination

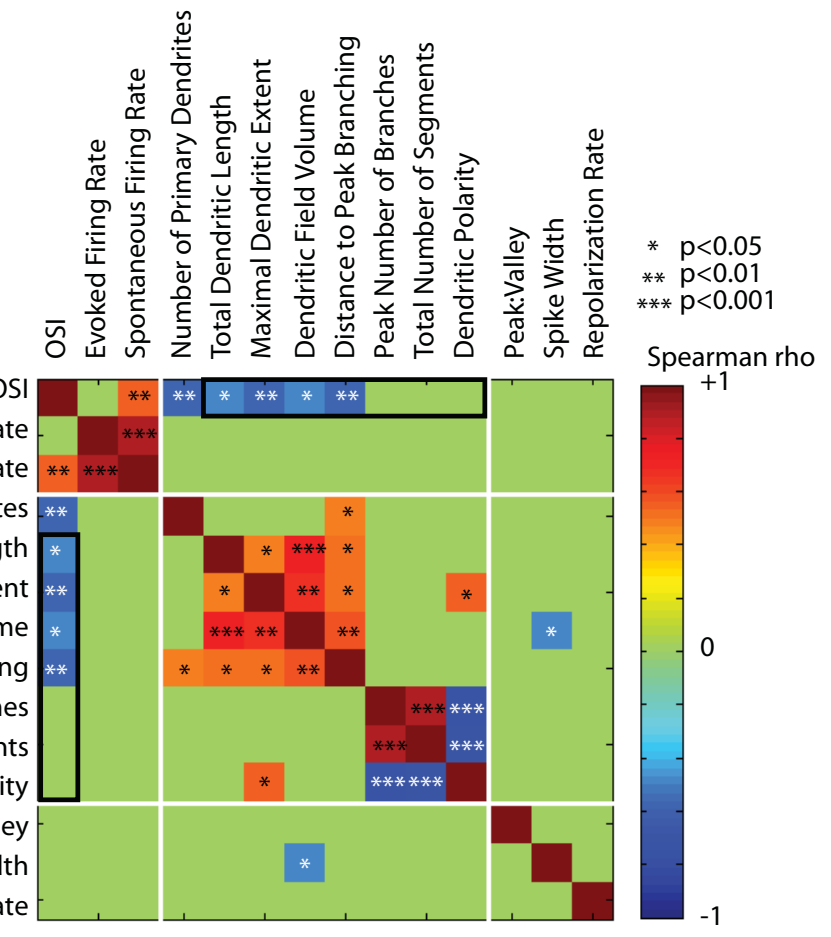

Figure 3. Correlations between all measured response properties, morphology, and spike shape parameters in the 20 recon-

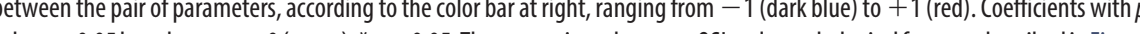
nd dendritic complexity. Three other clustered sets of related parameters show significant correlations, as expected: (1) firing rates, (2) measures of dendritic extent, and (3) measures of dendritic complexity. ${ }^{*} p<0.05,{ }^{* *} p<0.01,{ }^{* * *} p<0.001$.

of the reconstructions suggested that the dendritic morphology of $\mathrm{RFP}^{+}$neurons might vary systematically with orientation selectivity. The transition from larger dendritic trees to smaller dendritic trees as tuning becomes sharper is evident across the full population of reconstructed $\mathrm{RFP}^{+}$neurons, ordered by increasing OSI (Fig. $1 E$ ) and in three representative neurons spanning the full range of tuning (Fig. $1 F$ ).

We first estimated the spatial extent of the dendritic trees by measuring four parameters for each reconstructed $\mathrm{RFP}^{+}$neuron: (1) the total dendritic length of all of its dendritic processes, (2) the maximal dendritic extent (distance from the soma to the most distal dendritic tip), (3) the dendritic field volume (the convex volume enclosed by the dendritic tips), and (4) the distance of maximal dendritic branching from the soma (Sholl analysis). All four measures were significantly correlated with each other $(p<$ 0.05 , Spearman's rank correlation coefficient, here and below unless otherwise stated) and with orientation selectivity (Fig. 2A: dendritic length, $r=-0.49, p<0.05$; maximal dendritic extent, $r=-0.57, p<0.01$; dendritic field volume, $r=-0.48, p<0.05$; peak branching distance, $r=-0.58, p<0.01)$.

Next, we assessed dendritic complexity with two parameters: (1) the peak number of branches as a function of distance from the soma (Sholl analysis) and (2) the total number of dendritic segments. The two measures of dendritic complexity correlated with one another $(r=0.8, p<0.001)$, but unlike the measures of dendritic extent, neither measure correlated significantly with orientation selectivity (Fig. 2B: peak Sholl branches: $r=0.17, p=$ 0.47 ; total number of segments: $r=0.17, p=0.46$ ). Finally, ranking each dendritic segment by the number of branches separating it from the soma, orientation selectivity did not signifi- 
Table 1. Response features and morphological measurements of reconstructed RFP ${ }^{+}$neurons

\begin{tabular}{|c|c|c|c|c|c|c|c|c|c|c|c|c|c|c|}
\hline \multirow[b]{2}{*}{$\begin{array}{l}\text { Cell } \\
\text { ID }\end{array}$} & \multicolumn{3}{|c|}{ Response properties } & \multicolumn{8}{|c|}{ Morphology } & \multicolumn{3}{|c|}{ Spike shape } \\
\hline & OSI & $\begin{array}{l}\text { Evoked } \\
\text { firing } \\
\text { rate }(\mathrm{Hz})\end{array}$ & $\begin{array}{l}\text { Spontaneous } \\
\text { firing rate } \\
(\mathrm{Hz})\end{array}$ & $\begin{array}{l}\text { No. of } \\
\text { primary } \\
\text { dendrites }\end{array}$ & $\begin{array}{l}\text { Total } \\
\text { dendritic } \\
\text { length }(\mathrm{mm})\end{array}$ & $\begin{array}{l}\text { Maximal } \\
\text { dendritic } \\
\text { extent }(\mu \mathrm{m})\end{array}$ & $\begin{array}{l}\text { Dendritic field } \\
\text { volume }\left(\mathrm{mm}^{3}\right)\end{array}$ & $\begin{array}{l}\text { Distance of Sholl } \\
\text { peak from the } \\
\text { soma }(\mu \mathrm{m})\end{array}$ & $\begin{array}{l}\text { Peak no. } \\
\text { of Sholl } \\
\text { crossings }\end{array}$ & $\begin{array}{l}\text { Total no. of } \\
\text { dendritic } \\
\text { segments }\end{array}$ & DPI & $\begin{array}{l}\text { Peak: } \\
\text { valley }\end{array}$ & $\begin{array}{l}\text { Repolarization } \\
\text { rate }\end{array}$ & $\begin{array}{l}\text { Spike } \\
\text { width } \\
\text { (ms) }\end{array}$ \\
\hline 1 & 0.09 & 5.5 & 1.7 & 7 & 2.590 & 220 & 0.00465 & 92 & 11 & 26 & 0.75 & 23.9 & 0.5 & 2.8 \\
\hline 2 & 0.10 & 17.0 & 3.4 & 5 & 1.139 & 200 & 0.00027 & 60 & 6 & 26 & 1 & 0.9 & 1.5 & 2.6 \\
\hline 3 & 0.10 & 7.5 & 0.8 & 5 & 1.323 & 200 & 0.00052 & 65 & 6 & 16 & 0.85 & 13.0 & 0.5 & 2.9 \\
\hline 4 & 0.16 & 10.8 & 6.6 & 5 & 2.197 & 500 & 0.00398 & 83 & 5 & 15 & 0.82 & 1.3 & 1.6 & 1.9 \\
\hline 5 & 0.17 & 14.3 & 4.1 & 8 & 5.646 & 280 & 0.00436 & 95 & 15 & 52 & 0.82 & 1.1 & 3.4 & 1.9 \\
\hline 6 & 0.19 & 3.0 & 0.4 & 8 & 4.726 & 160 & 0.00177 & 71 & 20 & 53 & 0.3 & 1.2 & 1.3 & 1.1 \\
\hline 7 & 0.20 & 5.8 & 0.7 & 8 & 1.523 & 140 & 0.00094 & 69 & 18 & 45 & 0.3 & 1.1 & 2.0 & 1.1 \\
\hline 8 & 0.20 & 10.5 & 3.0 & 6 & 3.982 & 140 & 0.00059 & 65 & 12 & 31 & 0.53 & 0.9 & 7.2 & 3.0 \\
\hline 9 & 0.21 & 0.8 & 0.1 & 5 & 3.597 & 200 & 0.00135 & 76 & 12 & 34 & 0.44 & 3.1 & 1.7 & 2.8 \\
\hline 10 & 0.30 & 2.3 & 0.3 & 9 & 2.316 & 180 & 0.00108 & 50 & 12 & 48 & 0.09 & 0.3 & 3.0 & 2.8 \\
\hline 11 & 0.36 & 2.8 & 2.2 & 7 & 1.053 & 180 & 0.00080 & 86 & 8 & 23 & 0.99 & 1.6 & 0.2 & 1.2 \\
\hline 12 & 0.43 & 1.0 & 0.1 & 6 & 1.340 & 160 & 0.00071 & 66 & 14 & 37 & 0.22 & 1.1 & 1.8 & 1.1 \\
\hline 13 & 0.44 & 0.5 & 0.0 & 3 & 2.479 & 160 & 0.00034 & 76 & 7 & 23 & 0.76 & 16.2 & 1.1 & 3.2 \\
\hline 14 & 0.55 & 1.3 & 0.3 & 7 & 3.126 & 300 & 0.00120 & 43 & 7 & 18 & 0.91 & 1.4 & 2.1 & 1.9 \\
\hline 15 & 0.60 & 0.5 & 0.0 & 7 & 2.095 & 180 & 0.00145 & 75 & 16 & 45 & 0.19 & 0.8 & 0.2 & 1.1 \\
\hline 16 & 0.73 & 1.8 & 0.7 & 5 & 1.942 & 200 & 0.00038 & 67 & 7 & 22 & 0.59 & 1.3 & 2.2 & 1.1 \\
\hline 17 & 0.74 & 4.5 & 0.9 & 8 & 0.606 & 120 & 0.00026 & 43 & 9 & 26 & 0.47 & 2.5 & 5.0 & 3.1 \\
\hline 18 & 0.76 & 1.0 & 0.2 & 9 & 1.189 & 160 & 0.00064 & 50 & 14 & 47 & 0.16 & 2.5 & 2.2 & 2.7 \\
\hline 19 & 0.76 & 2.1 & 0.0 & 11 & 0.970 & 80 & 0.00011 & 36 & 15 & 46 & 0.21 & 1.0 & 3.0 & 3.0 \\
\hline 20 & 0.87 & 1.3 & 0.3 & 8 & 0.792 & 100 & 0.00010 & 42 & 10 & 41 & 0.63 & 17.9 & 0.2 & 3.4 \\
\hline
\end{tabular}

Cells are listed in order of increasing $0 \mathrm{SI}$, consistent with the ordering of the reconstructions in Figure $1 E$, and cell IDs correspond to those indicated in Figures $1 F$ and $2, A$ and $B$.

cantly correlate with the number of segments of low or high order ( $p>0.1$ for all ranks).

To assess whether the directionality of dendritic branching correlated with the orientation selectivity of $\mathrm{RFP}^{+}$neurons, the angles of dendritic branches and tips from the soma were calculated in each of the three 2D planes. The polarity in each dimension was quantified by vector averaging, to obtain a DPI. The maximum DPI was not correlated to orientation selectivity, as both highly tuned and broadly tuned $\mathrm{RFP}^{+}$neurons could have high DPIs $(r=-0.17, p=0.57)$. The correlations between all measured response, morphological, and electrophysiological parameters are summarized in Figure 3.

Together, these results suggest that $\mathrm{PV}^{+}$neurons with sharper tuning extend their branches over shorter distances but maintain similar dendritic complexity than do more broadly tuned $\mathrm{PV}^{+}$ neurons, which send similarly complex processes across longer distances. All results for reconstructed $\mathrm{RFP}^{+}$neurons are displayed in Table 1.

For comparison, we also reconstructed $9 \mathrm{GFP}^{+}$pyramidal neurons from the Thy-GFP-S mouse line (Feng et al., 2000). Example reconstructions are shown in Figure $4 A$, where the basal and apical processes are color-coded, and morphological and response parameters are summarized in Table 2. Furthermore, although our dendritic measurements in vivo are well within the ranges reported previously for cortical basket cells (Helmstaedter et al., 2009; Zaitsev et al., 2009), as an additional control, we performed a separate set of morphological measurements in vitro for comparison with the in vivo measurements. We sectioned V1 coronally, collected $z$-stacks of $\mathrm{RFP}^{+}$neurons in vitro, and reconstructed $8 \mathrm{RFP}^{+}$neurons in similar detail as those imaged in vivo (Fig. 4B). The Sholl profiles of the $\mathrm{RFP}^{+}$neurons imaged in vitro were similar to the Sholl profiles of the $\mathrm{RFP}^{+}$neurons imaged in vivo (Fig. $4 B$ ), as were the total dendritic lengths (Fig. 4C). None of the Sholl parameters (peak number of crossings, $p=0.28$; distance of peak from soma, $p=0.22$; profile radius, $p=0.39$; for each comparison: $n=8 \mathrm{RFP}^{+}$neurons imaged in vitro, $n=20$ $\mathrm{RFP}^{+}$neurons imaged in vivo) nor the total dendritic length ( $p=$
0.30) was significantly different between the cells imaged in vivo and in vitro.

\section{Orientation preference maps of $\mathrm{PV}^{+}$and $\mathrm{PV}^{-}$neurons}

The correlation between sharper orientation selectivity of $\mathrm{PV}^{+}$ neurons and smaller dendritic lengths and arbor extents suggested that $\mathrm{PV}^{+}$neurons might derive their tuning by sampling their cortical neighborhood, and sharper tuning may reflect focal sampling of locally homogeneous orientation representations. We thus examined the relationship between the tuning of $\mathrm{PV}^{+}$ neurons and surrounding neurons in the local V1 orientation map. Specifically, we used targeted, high-speed, two-photon calcium imaging (Wilson et al., 2012, 2013) to measure the orientation preferences of visually responsive $\mathrm{RFP}^{+} / \mathrm{PV}^{+}$neurons and their neighbors (Fig. 5A-C). Among imaged cells, 77 of 105 $\mathrm{RFP}^{+} / \mathrm{PV}^{+}$neurons and 1393 of $1601 \mathrm{RFP}^{-}$neurons in four mice were visually responsive.

The preferred orientations of cells and their neighbors across the field of view were then compared (Fig. $5 A-C$ ). We identified $\mathrm{RFP}^{+}$cells with a range of OSIs, including high and low OSIs (Fig. 5D). The local orientation scatter surrounding each cell was calculated by measuring the difference between that cell's preferred orientation and those of the neighboring cells within 60 , 90, 120, or $240 \mu \mathrm{m}$ (Fig. $5 E$, pooling all $\mathrm{RFP}^{+}$and $\mathrm{RFP}^{-}$cells from 4 animals); these distances included the maximal dendritic extent for highly tuned cells $(<150 \mu \mathrm{m})$, and the maximal dendritic extent of most broadly tuned cells $(\sim 250 \mu \mathrm{m}$; Fig. $2 A)$. The orientation scatter surrounding both $\mathrm{RFP}^{+}$and $\mathrm{RFP}^{-}$neurons increased with distance, being significantly greater at $240 \mu \mathrm{m}$ than at 60 or $90 \mu \mathrm{m}\left(p<0.05\right.$ comparing scatter of $\mathrm{RFP}^{+}$or $\mathrm{RFP}^{-}$neurons at 60 and $90 \mu \mathrm{m}$ with $240 \mu \mathrm{m}$ ), reflecting the existence of local homogeneities in the orientation map that dissipate at larger distance scales.

However, the scatter surrounding $\mathrm{RFP}^{+}$neurons was significantly lower than the scatter surrounding $\mathrm{RFP}^{-}$neurons at all distance scales (60 $\mu \mathrm{m}, p<0.01 ; 90 \mu \mathrm{m}, p<0.01 ; 120 \mu \mathrm{m}, p<$ $0.01 ; 240 \mu \mathrm{m}, p<0.01)$; that is, $\mathrm{RFP}^{+}$neurons tended to have 

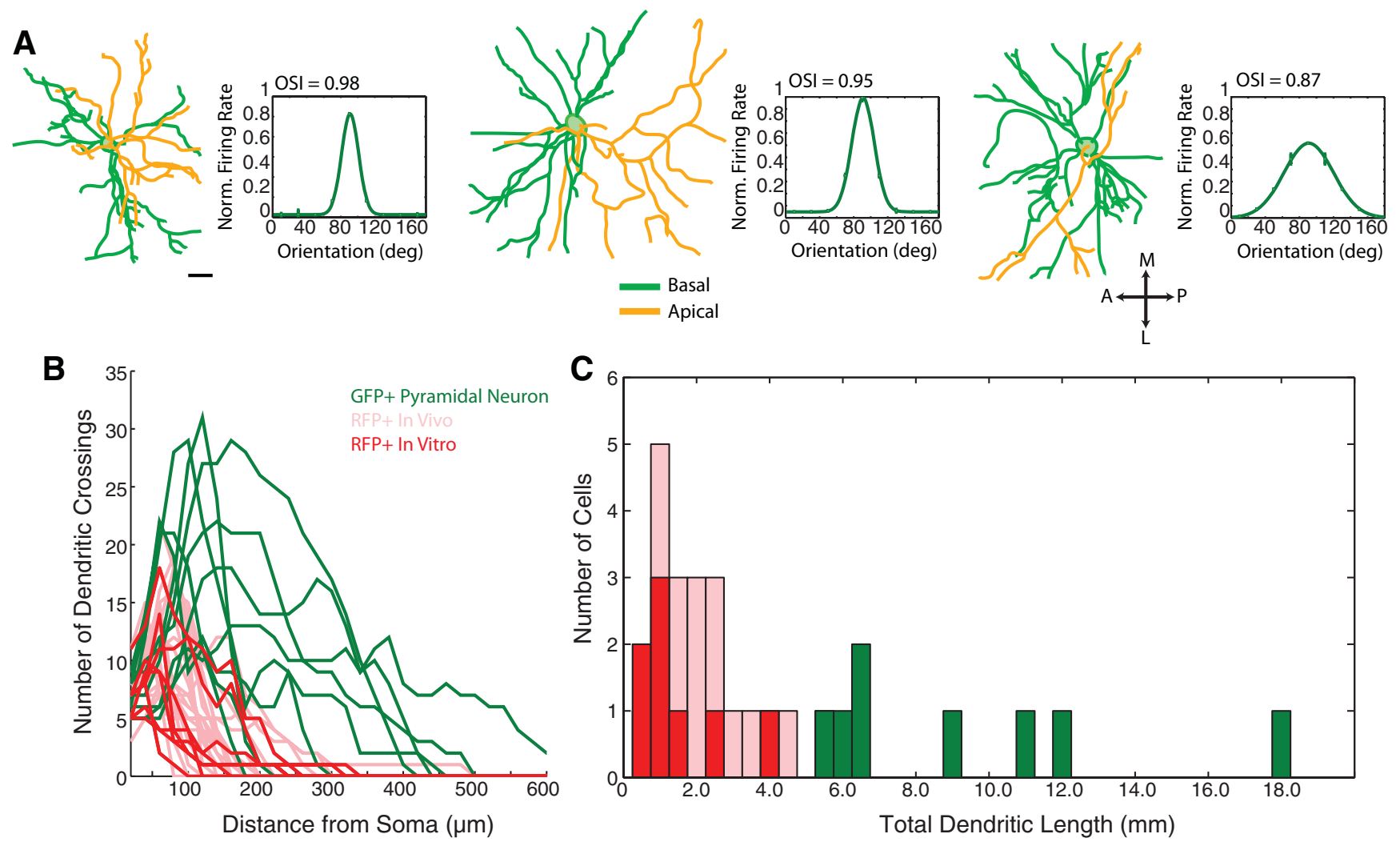

Figure 4. Control dendritic reconstructions of pyramidal neurons in vivo, $\mathrm{RFP}^{+} / \mathrm{PV}^{+}$neurons in vitro, and comparison with in vivo reconstructions of $\mathrm{RFP}^{+} / \mathrm{PV}^{+}$neurons showing similar representations of full dendritic morphologies. $A$, For comparison, pyramidal neurons from the Thy 1-GFPS mouse line were reconstructed. Reconstructions of three example pyramidal neurons are presented as in Figure $1 E-F$, with apical processes colored in yellow and basal processes in green. Scale bar, $20 \mu \mathrm{m}$. $\boldsymbol{B}$, Dendritic morphology is similar in RFP ${ }^{+}$neurons reconstructed in vivo and in vitro, and distinct from GFP ${ }^{+}$pyramidal neurons. The Sholl profiles of the $\mathrm{RFP}^{+} \mathrm{PV}^{+}$neurons imaged in vitro (bold red) and GFP ${ }^{+}$pyramidal neurons imaged in vivo are superimposed on the in vivo RFP ${ }^{+}$data from Figure 2 (pink). The in vitro Sholl profiles overlap extensively with the in vivo RFP ${ }^{+}$Sholl profiles. Peak number of crossings $(p=0.28)$, distance of the peak from the soma ( $p=$ $0.22)$, and radius $(p=0.39$ ) of the Sholl profiles were statistically similar in the in vitro and in vivo imaged cells, and distinct from pyramidal neurons $(p<0.001)$. C, Histogram of the total dendritic length of GFP ${ }^{+}$pyramidal neurons (green), $\operatorname{RFP}^{+}$neurons imaged in vitro (red), and RFP ${ }^{+}$neurons imaged in vivo (pink). The total dendritic length was statistically similar ( $p=0.30$ ) between the two sets of RFP ${ }^{+}$cells; however, both groups of RFP ${ }^{+}$neurons had shorter dendrites than the GFP ${ }^{+}$pyramidal neurons $(p<0.001)$. The morphological similarity between reconstructions of $\mathrm{RFP}^{+}$neurons in vivo and in vitro suggests that in vivo imaging fully captured the dendritic arbors of these neurons.

Table 2. Response features and morphological measurements of reconstructed GFP ${ }^{+}$pyramidal neurons in Figure 4

\begin{tabular}{|c|c|c|c|c|c|c|c|c|c|c|c|}
\hline \multirow[b]{2}{*}{ Cell ID } & \multicolumn{3}{|c|}{ Response properties } & \multicolumn{8}{|l|}{ Morphology } \\
\hline & OSI & $\begin{array}{l}\text { Evoked firing } \\
\text { rate }(\mathrm{Hz})\end{array}$ & $\begin{array}{l}\text { Spontaneous } \\
\text { firing rate } \\
(\mathrm{Hz})\end{array}$ & $\begin{array}{l}\text { No. of primary } \\
\text { dendrites }\end{array}$ & $\begin{array}{l}\text { Total dendritic } \\
\text { length }(\mathrm{mm})\end{array}$ & $\begin{array}{l}\text { Maximal dendritic } \\
\text { extent }(\mu \mathrm{m})\end{array}$ & $\begin{array}{l}\text { Dendritic field } \\
\text { volume } \\
\left(\mathrm{mm}^{3}\right)\end{array}$ & $\begin{array}{l}\text { Distance of Sholl peak from } \\
\text { the soma }(\mu \mathrm{m})\end{array}$ & $\begin{array}{l}\text { Peak no. of Sholl } \\
\text { crossings }\end{array}$ & $\begin{array}{l}\text { Total no. of } \\
\text { dendritic } \\
\text { segments }\end{array}$ & DPI \\
\hline 2 & 0.61 & 0.75 & 0.39 & 5 & 0.891 & 500 & 0.05238 & 191 & 12 & 44 & 0.82 \\
\hline 3 & 0.80 & 0.50 & 0.00 & 8 & 0.636 & 180 & 0.00209 & 70 & 19 & 98 & 0.98 \\
\hline 4 & 0.85 & 0.50 & 0.22 & 5 & 0.558 & 440 & 0.01100 & 160 & 9 & 27 & 0.93 \\
\hline 7 & 0.96 & 0.25 & 0.00 & 6 & 1.187 & 300 & 0.00104 & 100 & 26 & 70 & 0.69 \\
\hline 8 & 1.00 & 1.25 & 0.30 & 9 & 0.645 & 240 & 0.00452 & 77 & 20 & 72 & 0.69 \\
\hline 9 & 1.00 & 0.50 & 0.29 & 6 & 1.816 & 460 & 0.05987 & 208 & 17 & 52 & 0.77 \\
\hline
\end{tabular}

more similar orientation preferences to those of neighboring cells compared with $\mathrm{RFP}^{-}$neurons. To examine the validity of this difference, we scrambled the orientation preferences among all of the cells in the field of view, maintaining their spatial locations and $\mathrm{RFP}^{+} / \mathrm{RFP}^{-}$identities, and again measured the scatter surrounding the $\mathrm{RFP}^{+}$neurons. Indeed, the true scatter surrounding $\mathrm{RFP}^{+}$neurons was less than the scatter surrounding $\mathrm{RFP}^{+}$ neurons when the orientation preferences had been resampled among the cells in the field of view (Fig. 5E; $60 \mu \mathrm{m}, p<0.01 ; 90$ $\mu \mathrm{m}, p<0.01 ; 120 \mu \mathrm{m}, p<0.01 ; 240 \mu \mathrm{m}, p<0.01)$. RFP ${ }^{-}$ neurons, on the other hand, had similar scatter in the intact and scrambled cases at all distances examined $(p>0.2)$. Thus, $\mathrm{PV}^{+}$ neurons more closely resemble the orientation preferences of neighboring cells compared with $\mathrm{RFP}^{-}$neurons, and their location with the orientation map reflects local homogeneities in orientation representation that may contribute to their orientation selectivity.

\section{Discussion}

We have described the orientation selectivity of parvalbuminexpressing $\left(\mathrm{PV}^{+}\right)$inhibitory interneurons in the mouse primary 
A

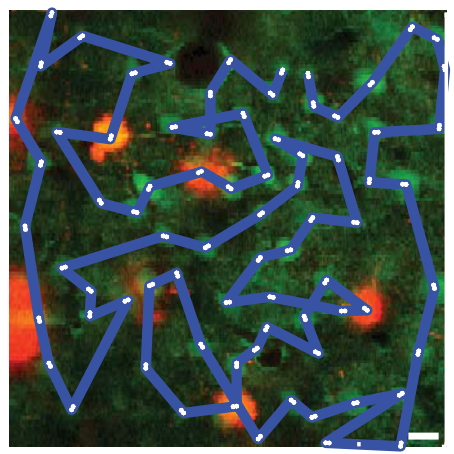

B

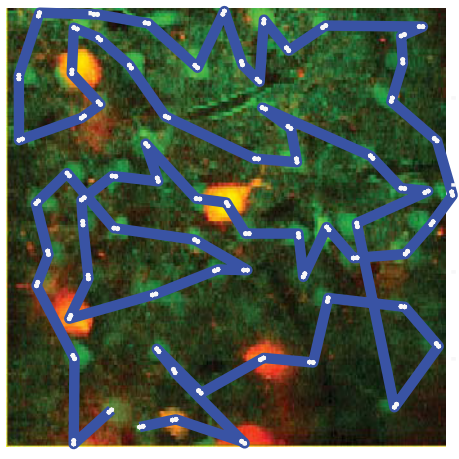

C

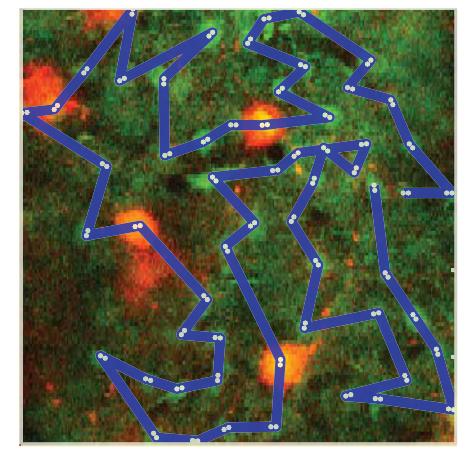

D

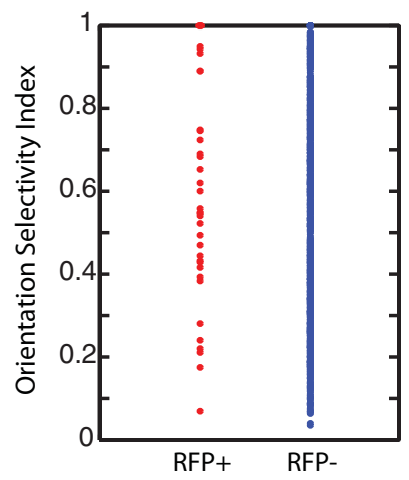

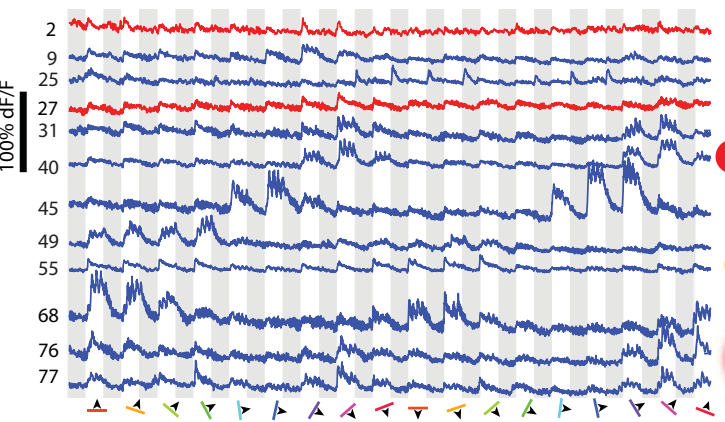
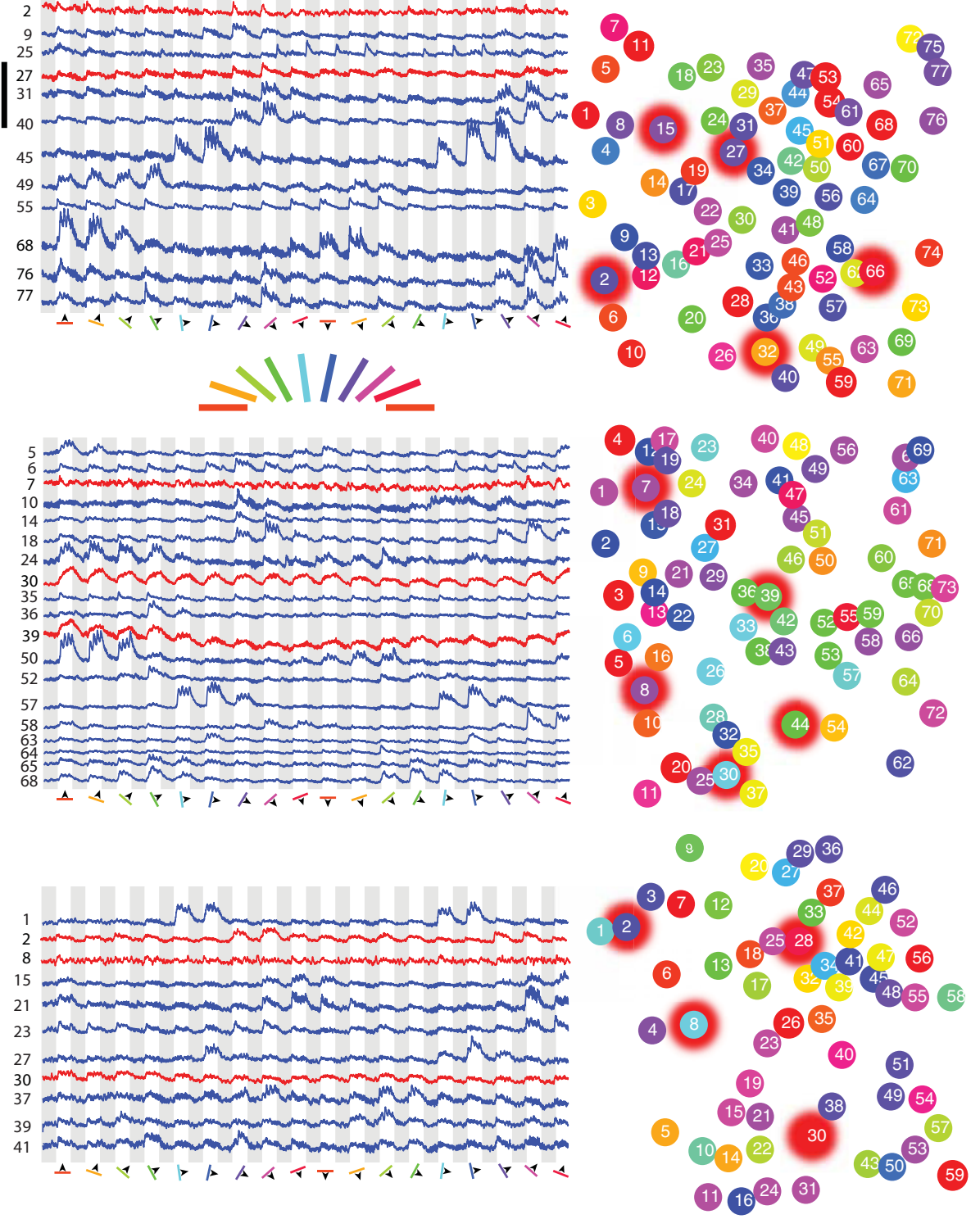

E

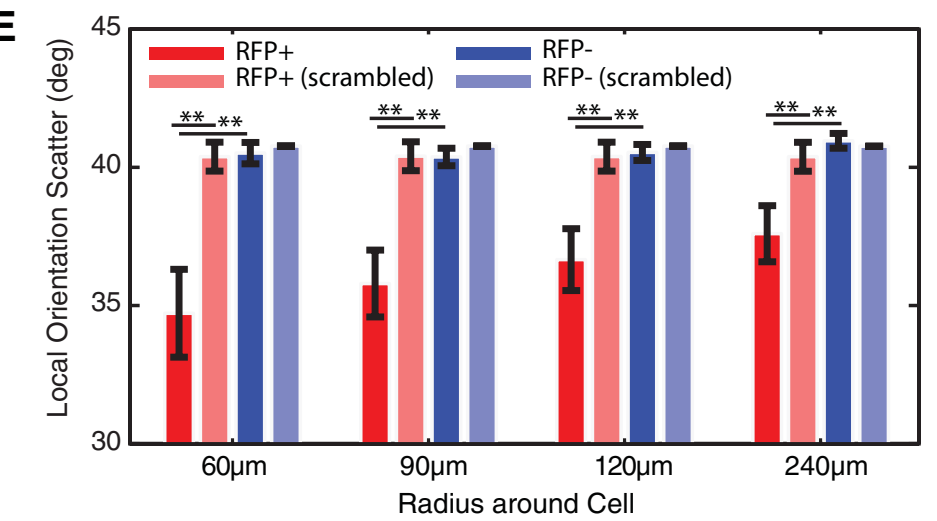

Figure 5. RFP ${ }^{+}$neurons tend to share the orientation preferences of their neighbors. $A-C$, Left column, $\mathrm{RFP}^{+}$neurons (red) and surrounding RFP ${ }^{-}$neurons were loaded with the calcium dye Oregon Green Bapta-1AM (green). Three representative networks are shown. The blue lines indicate the scan paths used to image calcium responses. White asterisks indicate the first and last pixels from which each cell's fluorescence response was collected within the scan path. Scale bar, $10 \mu \mathrm{m}$. Middle column, Example fluorescent responses to the 18 episodically presented drifting gratings (18 directions; gray represents $4 \mathrm{~s}$ OFF; white represents $4 \mathrm{~s} 0 \mathrm{~N}$ ), from cells in each of the example networks (blue represents $\mathrm{RFP}^{-}$neuron responses; red represents RFP ${ }^{+}$neuron responses). Right column, Each neuron is color-coded by its preferred orientation, and RFP ${ }^{+}$neurons are indicated by red halos. A, RFP ${ }^{+}$OSIs: cell \#2, $0.23 ; \# 15,0.84 ; \# 27,0.80 ; \# 32,0.29 ; \# 66,0.48 . \boldsymbol{B}, \mathrm{RFP}{ }^{+}$OSIs: cell \#7, 0.92; \#8, 0.6; \#30,0.32; \#39, 0.59; \#44,0.38. C, RFP ${ }^{+}$OSIs: cell \#2, 0.74; \#8,0.31;\#28,0.51;\#30,0.35. D, The OSI spanned the full range from 0 (untuned) to 1 (highly tuned) in both RFP ${ }^{+}$ (red) and RFP- (blue) neurons, consistent with the electrophysiology measurements of Figure 1.E, The local scatter in orientation preference surrounding each neuron within expanding intercell distances (red represents RFP ${ }^{+}$neurons; pink, RFP ${ }^{+}$in same networks with scrambled orientation preferences; dark blue, RFP ${ }^{-}$neurons; light blue, RFP ${ }^{-}$in same networks with scrambled orientation preferences). The scatter surrounding RFP ${ }^{+}$neurons was significantly lower than the scatter surrounding RFP ${ }^{-}$neurons $(p<0.01)$, or RFP ${ }^{+}$neurons in scrambled networks $(p<$ 0.01 ). Error bars indicate SEM. ${ }^{* *} p<0.01$. 
visual cortex (V1), using two-photon targeted cell-attached recordings. Although $\mathrm{PV}^{+}$neurons are less selective for orientation on average than the rest of the V1 neuronal population, the distribution of orientation selectivity in $\mathrm{PV}^{+}$neurons includes highly tuned cells in addition to broadly tuned cells. This diversity of tuning correlates with dendritic morphology: highly tuned $\mathrm{PV}^{+}$neurons have shorter total dendritic lengths, maximal branching closer to the soma, smaller dendritic field volumes, and shorter maximal dendritic extents compared with broadly tuned $\mathrm{PV}^{+}$neurons. Dendritic branching complexity, however, shows no relation to tuning. Furthermore, the orientation selectivity of $\mathrm{PV}^{+}$neurons is more similar to that of their local neighbors compared with non- $\mathrm{PV}^{+}$neurons. Thus, the tuning of $\mathrm{PV}^{+}$ neurons may derive from sampling of local inputs coupled with their dendritic morphology: highly tuned neurons, for example, may derive their tuning by sparsely sampling a homogeneous local population with short, proximally branched, dendrites, whereas broadly tuned neurons may derive their tuning by extensively sampling a more heterogeneous population with longer, distally branched dendrites.

Several studies have now examined the orientation selectivity of inhibitory neurons in the mouse visual cortex; we and others have described the existence of both highly tuned and broadly tuned inhibitory neurons (Niell and Stryker, 2008; Ma et al., 2010; Runyan et al., 2010; Zariwala et al., 2011), whereas others have described only broadly tuned inhibitory neurons (Sohya et al., 2007; Liu et al., 2009; Kerlin et al., 2010). In the present study, we sampled a large number of $\mathrm{PV}^{+}$inhibitory interneurons $(n=$ 80 visually responsive $\mathrm{PV}^{+}$neurons) to describe the distribution of orientation selectivity in this population more reliably, finding an overall more broadly tuned distribution than the rest of the V1 population, but a significant number of sharply tuned neurons as well. Differences in targeting and recording methods could account for the smaller, highly tuned, subclass missing from some studies (Hasenstaub and Callaway, 2010), as each study has used a unique combination of transgenic mice and recording techniques (Liu et al., 2009; Kerlin et al., 2010; Ma et al., 2010).

The existence of functionally diverse $\mathrm{PV}^{+}$neurons implies that these neurons may derive their inputs in different ways. The dendritic trees of $\mathrm{PV}^{+}$neurons were carefully and completely reconstructed in this study (Fig. 1). Fine-resolution $z$-stacks captured the full dorsal-ventral extent of the dendritic trees, whereas post hoc image processing to enhance the image contrast and careful manual tracing allowed each fine dendritic process to be traced through its full extent. $\mathrm{PV}^{+}$neurons imaged in slices and reconstructed with identical methodology yielded highly similar dendritic lengths and Sholl analysis results (Fig. 4). Furthermore, the total dendritic lengths that we measured in vivo $(0.9-5.6 \mathrm{~mm}$; mean $2.2 \mathrm{~mm}$ ) are similar to those described by others for inhibitory basket neurons that were imaged in vitro (Wang et al., 2002, mean $2.3 \mathrm{~mm}$; Kawaguchi et al., 2006, mean 2.9 mm; Helmstaedter et al., 2009).

The finding that the orientation selectivity of $\mathrm{PV}^{+}$neurons is correlated with the orientation distribution of cells in their local neighborhood is in agreement with recent work suggesting that inhibitory neurons receive strong local inputs from nearby cells (Bock et al., 2011; Hofer et al., 2011). Because V1 in rodents lacks the highly ordered orientation maps found in carnivores, it has been commonly assumed that orientation preferences are uniformly random across the rodent visual cortex (Ohki and Reid, 2007). However, our results in mouse V1 confirm longstanding hints that local clustering of orientation preferences exists (Dräger, 1975; Kerlin et al., 2010). Local coherence in the orien- tation map, combined with sparse and highly local sampling of inputs by some inhibitory neurons, could lead to high selectivity in these cells. Future studies examining the outputs of highly tuned and broadly tuned inhibitory neurons will determine whether these neurons also select their targets according to such spatial rules, or in functionally specific ways (Yoshimura and Callaway, 2005; Fino and Yuste, 2011; Packer and Yuste, 2011; Wilson et al., 2012).

\section{References}

Adesnik H, Bruns W, Taniguchi H, Huang ZJ, Scanziani M (2012) A neural circuit for spatial summation in visual cortex. Nature 490:226-231. CrossRef Medline

Atallah BV, Bruns W, Carandini M, Scanziani M (2012) Parvalbuminexpressing interneurons linearly transform cortical responses to visual stimuli. Neuron 73:159-170. CrossRef Medline

Blatow M, Rozov A, Katona I, Hormuzdi SG, Meyer AH, Whittington MA, Caputi A, Monyer H (2003) A novel network of multipolar bursting interneurons generates $\theta$ frequency oscillations in neocortex. Neuron 38: 805-817. CrossRef Medline

Bock DD, Lee WC, Kerlin AM, Andermann ML, Hood G, Wetzel AW, Yurgenson S, Soucy ER, Kim HS, Reid RC (2011) Network anatomy and in vivo physiology of visual cortical neurons. Nature 471:177-182. CrossRef Medline

Brainard DH (1997) The psychophysics toolbox. Spat Vis 10:433-436.

Burkhalter A (2008) Many specialists for suppressing cortical excitation. Front Neurosci 2:155-167. CrossRef Medline

Cardin JA, Carlén M, Meletis K, Knoblich U, Zhang F, Deisseroth K, Tsai LH, Moore CI (2009) Driving fast-spiking cells induces gamma rhythm and controls sensory responses. Nature 459:663-667. CrossRef Medline

Chow A, Erisir A, Farb C, Nadal MS, Ozaita A, Lau D, Welker E, Rudy B (1999) $\mathrm{K}(+)$ channel expression distinguishes subpopulations of parvalbumin- and somatostatin-containing neocortical interneurons. J Neurosci 19:9332-9345. Medline

Dombeck DA, Graziano MS, Tank DW (2009) Functional clustering of neurons in motor cortex determined by cellular resolution imaging in awake behaving mice. J Neurosci 29:13751-13760. CrossRef Medline

Dräger UC (1975) Receptive fields of single cells and topography in mouse visual cortex. J Comp Neurol 160:269-290. CrossRef Medline

Du J, Zhang L, Weiser M, Rudy B, McBain CJ (1996) Developmental expression and functional characterization of the potassium-channel subunit Kv3.1b in parvalbumin-containing interneurons of the rat hippocampus. J Neurosci 16:506-518. Medline

Feng G, Mellor RH, Bernstein M, Keller-Peck C, Nguyen QT, Wallace M, Nerbonne JM, Lichtman JW, Sanes JR (2000) Imaging neuronal subsets in transgenic mice expressing multiple spectral variants of GFP. Neuron 28:41-51. CrossRef Medline

Fino E, Yuste R (2011) Dense inhibitory connectivity in neocortex. Neuron 69:1188-1203. CrossRef Medline

Gutierrez H, Davies AM (2007) A fast and accurate procedure for deriving the Sholl profile in quantitative studies of neuronal morphology. J Neurosci Methods 163:24-30. CrossRef Medline

Han ZS (1994) Electrophysiological and morphological differentiation of chandelier and basket cells in the rat hippocampal formation: a study combining intracellular recording and intracellular staining with biocytin. Neurosci Res 19:101-110. CrossRef Medline

Hasenstaub AR, Callaway EM (2010) Paint it black (or red, or green): optical and genetic tools illuminate inhibitory contributions to cortical circuit function. Neuron 67:681-684. CrossRef Medline

Helm J, Akgul G, Wollmuth LP (2013) Subgroups of parvalbuminexpressing interneurons in layers $2 / 3$ of the visual cortex. J Neurophysiol 109:1600-1613. CrossRef Medline

Helmstaedter M, Sakmann B, Feldmeyer D (2009) L2/3 interneuron groups defined by multiparameter analysis of axonal projection, dendritic geometry, and electrical excitability. Cereb Cortex 19:951-962. CrossRef Medline

Hippenmeyer S, Vrieseling E, Sigrist M, Portmann T, Laengle C, Ladle DR, Arber S (2005) A developmental switch in the response of DRG neurons to ETS transcription factor signaling. PLoS Biol 3:e159. CrossRef Medline

Hofer SB, Ko H, Pichler B, Vogelstein J, Ros H, Zeng H, Lein E, Lesica NA, Mrsic-Flogel TD (2011) Differential connectivity and response dynam- 
ics of excitatory and inhibitory neurons in visual cortex. Nat Neurosci 14:1045-1052. CrossRef Medline

Isaacson JS, Scanziani M (2011) How inhibition shapes cortical activity. Neuron 72:231-243. CrossRef Medline

Kawaguchi Y, Karube F, Kubota Y (2006) Dendritic branch typing and spine expression patterns in cortical nonpyramidal cells. Cereb Cortex 16:696-711. CrossRef Medline

Kerlin AM, Andermann ML, Berezovskii VK, Reid RC (2010) Broadly tuned response properties of diverse inhibitory neuron subtypes in mouse visual cortex. Neuron 67:858-871. CrossRef Medline

Kisvárday ZF, Eysel UT (1993) Functional and structural topography of horizontal inhibitory connections in cat visual cortex. Eur J Neurosci 5:1558-1572. CrossRef Medline

Krimer LS, Zaitsev AV, Czanner G, Kröner S, González-Burgos G, Povysheva NV, Iyengar S, Barrionuevo G, Lewis DA (2005) Cluster analysis-based physiological classification and morphological properties of inhibitory neurons in layers 2-3 of monkey dorsolateral prefrontal cortex. J Neurophysiol 94:3009-3022. CrossRef Medline

Kuhlman SJ, Huang ZJ (2008) High-resolution labeling and functional manipulation of specific neuron types in mouse brain by Cre-activated viral gene expression. PLoS One 3:e2005. CrossRef Medline

Lee SH, Kwan AC, Zhang S, Phoumthipphavong V, Flannery JG, Masmanidis SC, Taniguchi H, Huang ZJ, Zhang F, Boyden ES, Deisseroth K, Dan Y (2012) Activation of specific interneurons improves V1 feature selectivity and visual perception. Nature 488:379-383. CrossRef Medline

Liu BH, Li P, Li YT, Sun YJ, Yanagawa Y, Obata K, Zhang LI, Tao HW (2009) Visual receptive field structure of cortical inhibitory neurons revealed by two-photon imaging guided recording. J Neurosci 29:10520-10532. CrossRef Medline

Lovett-Barron M, Turi GF, Kaifosh P, Lee PH, Bolze F, Sun XH, Nicoud JF, Zemelman BV, Sternson SM, Losonczy A (2012) Regulation of neuronal input transformations by tunable dendritic inhibition. Nat Neurosci 15: 423-430; S1-S3. CrossRef Medline

Lund JS, Lewis DA (1993) Local circuit neurons of developing and mature macaque prefrontal cortex: Golgi and immunocytochemical characteristics. J Comp Neurol 328:282-312. CrossRef Medline

Ma WP, Liu BH, Li YT, Huang ZJ, Zhang LI, Tao HW (2010) Visual representations by cortical somatostatin inhibitory neurons: selective but with weak and delayed responses. J Neurosci 30:14371-14379. CrossRef Medline

Majewska A, Yiu G, Yuste R (2000) A custom-made two-photon microscope and deconvolution system. Pflugers Arch 441:398-408. CrossRef Medline

Mariño J, Schummers J, Lyon DC, Schwabe L, Beck O, Wiesing P, Obermayer $\mathrm{K}$, Sur M (2005) Invariant computations in local cortical networks with balanced excitation and inhibition. Nat Neurosci 8:194-201. CrossRef Medline

Markram H, Toledo-Rodriguez M, Wang Y, Gupta A, Silberberg G, Wu C (2004) Interneurons of the neocortical inhibitory system. Nat Rev Neurosci 5:793-807. CrossRef Medline

Niell CM, Stryker MP (2008) Highly selective receptive fields in mouse visual cortex. J Neurosci 28:7520-7536. CrossRef Medline

Ohki K, Reid RC (2007) Specificity and randomness in the visual cortex. Curr Opin Neurobiol 17:401-407. CrossRef Medline

Packer AM, Yuste R (2011) Dense, unspecific connectivity of neocortical parvalbumin-positive interneurons: a canonical microcircuit for inhibition? J Neurosci 31:13260-13271. CrossRef Medline

Peng H, Ruan Z, Long F, Simpson JH, Myers EW (2010) V3D enables real- time 3D visualization and quantitative analysis of large-scale biological image data sets. Nat Biotechnol 28:348-353. CrossRef Medline

Pouille F, Scanziani M (2001) Enforcement of temporal fidelity in pyramidal cells by somatic feed-forward inhibition. Science 293:1159-1163. CrossRef Medline

Royer S, Zemelman BV, Losonczy A, Kim J, Chance F, Magee JC, Buzsáki G (2012) Control of timing, rate and bursts of hippocampal place cells by dendritic and somatic inhibition. Nat Neurosci 15:769-775. CrossRef Medline

Runyan CA, Schummers J, Van Wart A, Kuhlman SJ, Wilson NR, Huang ZJ, Sur M (2010) Response features of parvalbumin-expressing interneurons suggest precise roles for subtypes of inhibition in visual cortex. Neuron 67:847-857. CrossRef Medline

Schummers J, Mariño J, Sur M (2002) Synaptic integration by V1 neurons depends on location within the orientation map. Neuron 36:969-978. CrossRef Medline

Schummers J, Yu H, Sur M (2008) Tuned responses of astrocytes and their influence on hemodynamic signals in the visual cortex. Science 320:1638-1643. CrossRef Medline

Sohya K, Kameyama K, Yanagawa Y, Obata K, Tsumoto T (2007) GABAergic neurons are less selective to stimulus orientation than excitatory neurons in layer II/III of visual cortex, as revealed by in vivo functional $\mathrm{Ca}^{2+}$ imaging in transgenic mice. J Neurosci 27:21452149. CrossRef Medline

Somogyi P, Klausberger T (2005) Defined types of cortical interneurone structure space and spike timing in the hippocampus. J Physiol 562:9-26. CrossRef Medline

Vruwink M, Schmidt HH, Weinberg RJ, Burette A (2001) Substance P and nitric oxide signaling in cerebral cortex: anatomical evidence for reciprocal signaling between two classes of interneurons. J Comp Neurol 441:288-301. CrossRef Medline

Wang Y, Gupta A, Toledo-Rodriguez M, Wu CZ, Markram H (2002) Anatomical, physiological, molecular and circuit properties of nest basket cells in the developing somatosensory cortex. Cereb Cortex 12:395-410. CrossRef Medline

Wehr M, Zador AM (2003) Balanced inhibition underlies tuning and sharpens spike timing in auditory cortex. Nature 426:442-446. CrossRef Medline

Wilson NR, Runyan CA, Wang FL, Sur M (2012) Division and subtraction by distinct cortical inhibitory networks in vivo. Nature 488:343-348. CrossRef Medline

Wilson NR, Schummers J, Runyan CA, Yan SX, Chen RE, Deng Y, Sur M (2013) Two-way communication with neural networks in vivo using focused light. Nat Protoc 8:1184-1203. CrossRef Medline

Yan XX, Baram TZ, Gerth A, Schultz L, Ribak CE (1998) Co-localization of corticotropin-releasing hormone with glutamate decarboxylase and calcium-binding proteins in infant rat neocortical interneurons. Exp Brain Res 123:334-340. CrossRef Medline

Yoshimura Y, Callaway EM (2005) Fine-scale specificity of cortical networks depends on inhibitory cell type and connectivity. Nat Neurosci 8:1552-1559. CrossRef Medline

Zaitsev AV, Povysheva NV, Gonzalez-Burgos G, Rotaru D, Fish KN, Krimer LS, Lewis DA (2009) Interneuron diversity in layers $2-3$ of monkey prefrontal cortex. Cereb Cortex 19:1597-1615. CrossRef Medline

Zariwala HA, Madisen L, Ahrens KF, Bernard A, Lein ES, Jones AR, Zeng H (2011) Visual tuning properties of genetically identified layer $2 / 3$ neuronal types in the primary visual cortex of cre-transgenic mice. Front Syst Neurosci 4:162-116. CrossRef Medline 